\title{
Type-III supracondylar humerus fracture: functional outcome of open reduction and internal fixation after failed closed reduction
}

\author{
Shobha H. P., Vishwas K.*, Lingaraju K., Giridhar Kumar
}

Department of Orthopaedics, Mysore Medical College and Research Institute, Mysore, Karnataka, India

Received: 31 August 2020

Revised: 09 October 2020

Accepted: 11 October 2020

\author{
*Correspondence: \\ Dr. Vishwas K., \\ E-mail: vishwask77@gmail.com
}

Copyright: ( ) the author(s), publisher and licensee Medip Academy. This is an open-access article distributed under the terms of the Creative Commons Attribution Non-Commercial License, which permits unrestricted non-commercial use, distribution, and reproduction in any medium, provided the original work is properly cited.

\begin{abstract}
Background: To evaluate results of open reduction and internal fixation with Criss cross k-wires after failed closed reduction in Gartland type III Supracondylar fracture of humerus in our institution.

Methods: This prospective study was conducted at the Krishna Rajendra hospital affiliated to the orthopaedic department of Mysore medical college and research institute from December 2018 to December 2019. Twenty-five patients of type-III fracture of supracondylar humerus were included within the study. Consent was obtained from all patients. Under anaesthesia, closed reduction was attempted first. When 2-3 attempts of closed reduction failed, an open reduction and internal fixation with cross k-wires was performed. Fortnightly follow up was applied for the first 8 weeks then monthly for the next 4 months. The clinical outcome was evaluated using Flynn criteria.

Results: Out of 25 patients, 16 were male and 9 were female. Left side was involved in 17 patients and right side in 8 . Mean age was 6.9 years with age range from 3 to 12 years. Excellent or good results were obtained in $23(92 \%)$ patients and fair or poor in $2(8 \%)$.

Conclusions: We conclude that these fractures must be managed aggressively, by a specialised surgeon. Open reduction and internal fixation of severely displaced supracondylar fractures of the humerus is a safe and effective method when a satisfactory reduction can't be obtained by 2-3 attempts on closed method.
\end{abstract}

Keywords: Supracondylar, Humerus, Open reduction, K wiring

\section{INTRODUCTION}

Supracondylar fracture (SF) of the humerus is the commonest fracture at elbow in children and represents approximately $3 \%$ of all fractures in children. ${ }^{1,2}$ These fractures are seen within the first decade of life especially between ages 5 and eight years. ${ }^{2,3}$ SF of humerus are caused by fall on out stretched hand and is classified into two types, extension type and flexion type. ${ }^{5}$ $98.3 \%$ of the fractures are extension type and $1.7 \%$ are flexion type. ${ }^{3}$ Extension type are further classified as describe by garland in line with the degree of displacement of the distal fragment. ${ }^{2,6}$ Type I is un displaced fracture, type II is displaced with intact posterior cortex, and III is totally displaced with no contact between the fragments (Figure 1). ${ }^{7}$ The treatment modalities include forearm traction, overhead skeletal fraction, closed reduction and casting with or without percutaneous pinning and open reduction and internal fixation. ${ }^{8,9}$ Type III SF of humerus are treated by closed reduction and percutaneous $\mathrm{k}$-wires fixation if fracture pattern is stable and amenable to closed reduction. Open reduction and internal fixation is performed if a satisfactory reduction cannot be obtained by closed manipulation. ${ }^{10-13}$ Closed manipulations are better avoided in displaced type-III posterolateral fractures with neurovascular deficit because the neurovascular bundle can also be tethered within the fracture site and Brachialis. ${ }^{14}$ The indications for open reduction and internal fixation (ORIF) are failed closed reduction, 
fractures needing debridement and irrigation, and fractures associated with vascular injuries. Open reduction must be done carefully to avoid complications like cubitus varus or valgus deformities, myositis ossificans, elbow stiffness, neurovascular complications like brachial artery or ulnar nerve injury and compartment syndrome. ${ }^{15,16}$ The aim of this study was to judge the results of open reduction and internal fixation after failed close reduction in Gartland type III SF in our circumstances.

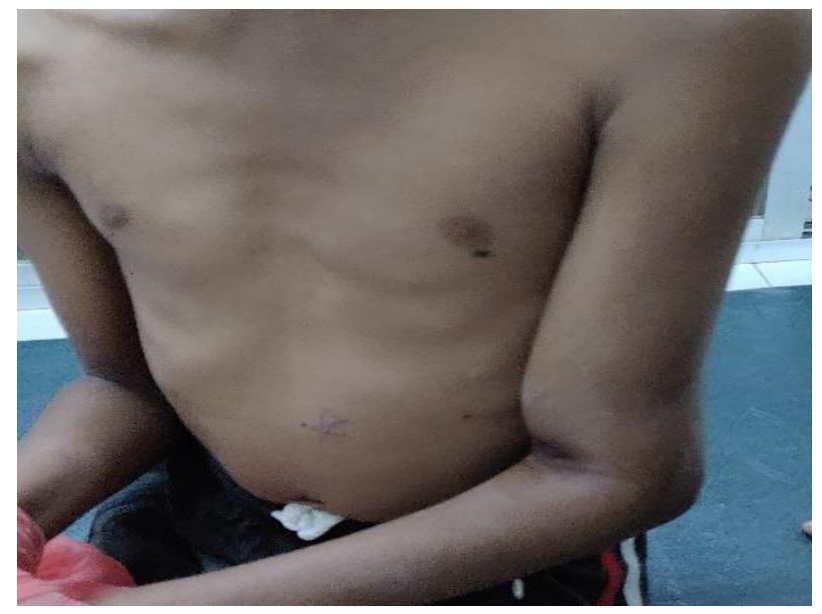

Figure 1: Initial presentation.

\section{METHODS}

This prospective study was conducted at the orthopaedic department of Mysore medical college and research institute from December 2018 to December 2019. Ethical clearance was obtained from institutional ethical committee, Mysore medical college and research institute and associated hospitals. 25 patients with closed Gartland type III SF of humerus were included within the study. Patients included were children 3 to 12 years old. Those with vascular injury were excluded from the study. All patients were admitted through accident and emergency department/casualty. Detailed history and clinical examination were performed on admission after obtaining written and consent. The patients were placed in posterior splint for temporary stabilization. Distal neurovascular status was monitored closely. Patients were prepared for the surgery.

Surgical technique used was under general anaesthesia, closed reduction was attempted first; within the event of its failure, a tourniquet was applied and posterior midline incision was given. ulnar nerve was identified, dissected and isolated. After elevating triceps muscle, the fracture side was cleaned, reduced and held with 2 cross k-wires of appropriate diameter. In most patients, Brachialis was found to be interposed between the 2 fragments and was the culprit behind the failed closed reduction. The ends of the wires were left outside the skin for removal afterwards. Skin was closed and posterior slab was applied.
Statistical software-SPSS version 22 and Microsoft excel 2007 were used for analysis of data.

\section{RESULTS}

The patients were followed up fortnightly for two months and thereafter monthly for six months. At day 10 , sutures were removed. At 3 weeks, k-wires and slab were removed without anaesthesia after taking a radiograph of the elbow. Range of motion exercises were started and final assessment was made at 6 months using Flynn criteria ${ }^{17}$ (Table 1).

All 25 patients completed their follow up; Out of 25 patients, 15 were male and 10 were female. Left side was involved in 17 patients and right side in 8 . Mean age was 6.9 years (age from 3 to 12 ). Outcome of procedure was as follows (Table 2).

Table 1: Flynn's criteria.

\begin{tabular}{|llll|}
\hline Results & Rating & $\begin{array}{l}\text { Loss of } \\
\text { carrying } \\
\text { angle }\end{array}$ & $\begin{array}{l}\text { Loss of } \\
\text { motion }\end{array}$ \\
\hline \multirow{3}{*}{ Satisfactory } & Excellent & $0^{0}-5^{0}$ & $0^{0}-5^{0}$ \\
\cline { 2 - 4 } & Good & $5^{0}-15^{0}$ & $5^{0}-15^{0}$ \\
\cline { 2 - 4 } Unsatisfactory & Fair & $10^{0}-15^{0}$ & $10^{0}-15^{0}$ \\
\hline
\end{tabular}

Table 2: Outcome of procedure according to Flynn criteria.

\begin{tabular}{|llc|}
\hline Number & & Percentage (\%) \\
\hline Excellent & 20 & 80 \\
\hline Good & 3 & 12 \\
\hline Fair & 1 & 4 \\
\hline Poor & 1 & 4 \\
\hline
\end{tabular}

Excellent or good results were obtained in $23(92 \%)$ patients. Poor result was due to cubitus varus in $1(4 \%)$ patient. Transient ulnar nerve palsy occurred in 1 (4.0\%) patient which completely recovered in three months. Pin tract infection in $2(8.0 \%)$ patients, which resolved with local care and oral antibiotic. Deep infection and compartment syndrome weren't encountered in our series.

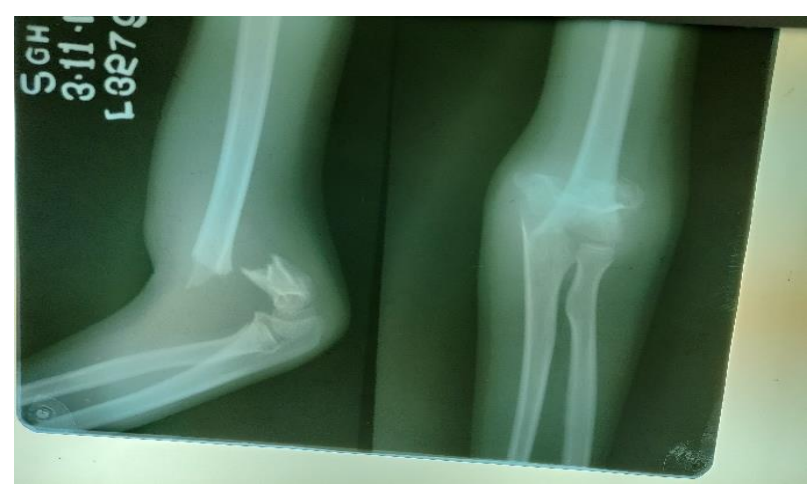

Figure 2: Initial X-ray. 


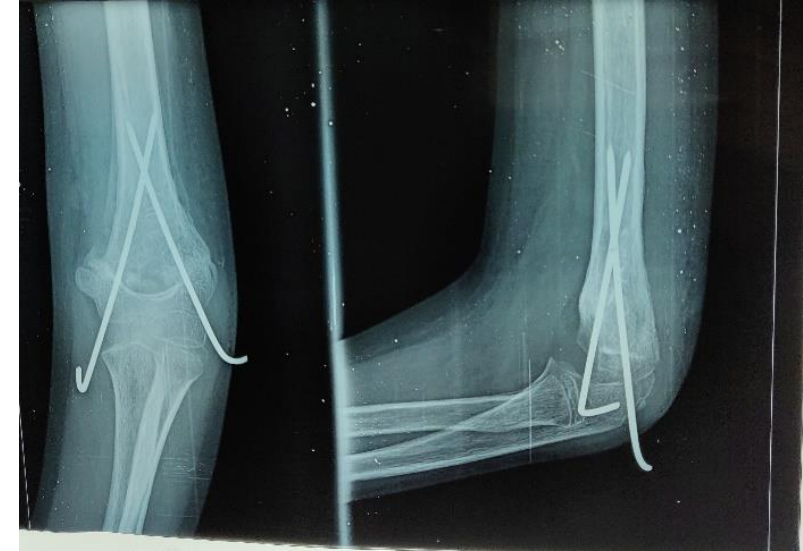

Figure 3: Post op week 3 X-ray.

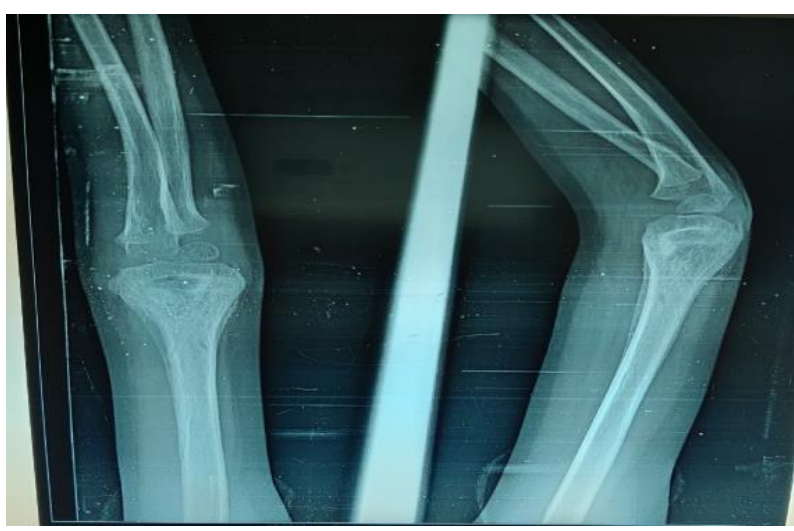

Figure 4: Post op month 3 X-ray.

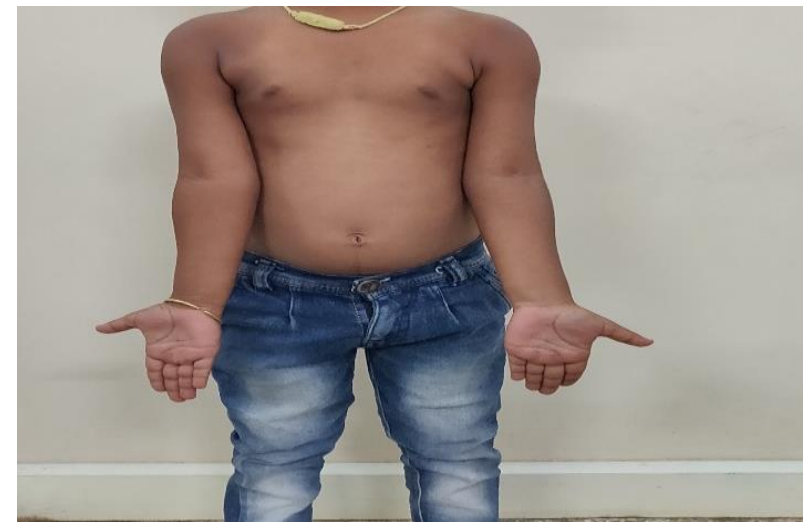

Figure 5: Post op month 3 clinical picture.

\section{DISCUSSION}

Supracondylar fractures of humerus are one of the most typical childhood injuries and account for $60 \%$ of all fractures about the elbow in children. ${ }^{18}$ In the treatment of type-III fractures the significant difficulty of closed reduction and casting is to hyperflex the elbow beyond 120 degree to keep up reduction, which isn't always possible because of loss of pulse on hyperflexion. Failure to try and do so increases the danger of losing reduction, because of loss of supporting effect of the triceps muscle. Another difficulty in closed reduction is that coronal tilt isn't always appreciated on radiograph, and therefore the fact unveils itself only if deformity has already occurred..$^{19,20}$ The aim of surgery is to securely create an adequately stable construct to forestall rotation of axis and coronal or sagittal tilt to avoid post-operative deformity. ${ }^{21}$ Closed reduction and percutaneous k-wires fixation is the preferred treatment of choice for the reducible fracture, but percutaneous pin fixation needs image intensifier and is related to iatrogenic cubital nerve injuries. ${ }^{22}$ Some surgeons would reserve ORIF for open fractures or for those related to vascular injury, as there's $1.4 \%$ incidence of myositis ossificans and no neurovascular deficit. ${ }^{23,24}$ The results of our study were resembling both local and international studies. In our study, excellent and good results of $92 \%$ are akin to earlier studies of Kamath (92.5\%) and Philip (82\%), Kumar (84\%), Ababneh (87\%) and Umer (100\%) et al. ${ }^{25-29}$ Another study by Diri et al reported good to excellent results in $91.8 \%$, like our results. ${ }^{30}$ Iatrogenic nerve injury was observed in 1 patient who recovered in three months without intervention. Overall patient satisfaction with reference to functions was excellent.

\section{CONCLUSION}

Type III supracondylar humerus fractures must be managed aggressively and open reduction internal fixation of severely displaced supracondylar fracture of humerus is a safe and effective option when a satisfactory reduction can't be obtained by 2-3 attempts of closed method.

\section{Funding: No funding sources}

\section{Conflict of interest: None declared}

Ethical approval: The study was approved by the institutional ethics committee, Mysore medical college and research institute and associated hospitals, Mysore570021, EC REG:ECR/134/Inst/KA/2013/RR-16

\section{REFERENCES}

1. Dimeglio A. Growth in Paediatric Orthopaedics in Mornay RT, Weinstein SL; Lovell and Winter's Paediatric Orthopaedics $6^{\text {th }}$ edition Philadelphia, Lippincott Williams and Wilkins, 2006:35-65.

2. Sawyer JR, Spence DD. Fracture and dislocations in children. In: Canale ST, Beaty JH,Frederick M Azar, editors- Campbell's operative orthopaedics. 13th ed. Philadelphia: Mosby. 2017;1433-40.

3. Cheng JC, Lam TP, Maffulli N. Epidemiological features of Supracondylar humerus fractures in Chinese children. J Pediatr Orthop B. 2001;10(1);637.

4. Mahan ST, May CD, Kocher MS operative management of displaced of Supracondylar humerus fractures in children. J Pediatr Orthop. 2007;27(5);551-6.

5. Minkowitz B, Busch MT. Supracondylar fracture of humerus, current trends and controversies. Orthop Clin North Am. 1994;25:581-94. 
6. Wilkins KE. Fractures and Dislocation of the Elbow Region. In Wilkins KE, King RE (eds). Fractures in Children. Philadelphia, JB Lippincott Company. 1991;3:509.

7. Gartland JJ. Management of supracondylar fracture of humerus in children. Surg Gynecol Obstet. 1959; 109:145-54

8. Khan MS, Sultan S, Ali MA, Khan A, Younis M. Comparison of percutaneous pinning with casting in supracondylar humeral fractures in children. J Ayub Med Coll Abottabad. 2005;17:33-6.

9. Dameron TB. Transverse fractures of the distal humerus in children. Instr Course Lect. 1981;30:224.

10. France J, Strong M. Deformity and functions in supracondylar fractures of the humerus in children variously treated by closed reduction and splinting, traction and percutaneous pinning. J Pediatr Orthop. 1992;12:494.

11. Paradis G, Lavallee P, Gagnon N, Lemire L. Supracondylar fractures of the humerus in children. Technique and results of crossed percutaneous K-wire fixation. Clin Orthop. 1993;297:231.

12. Nacht JL, Ecker ML, Chung SMK, Lotke PA, Das M. Supracondylar fractures of the humerus in children treated by closed reduction and percutaneous pinning. Clin Orthop. 1983;177:203.

13. Cheng JCY, Lam, TP, Shen WY. Closed reduction and percutaneous pinning for Type III displaced supracondylar fractures of the humerus in children. $\mathrm{J}$ Orthop Trauma. 1995;9:511.

14. Rasool MN, Naidoo KS. Supracondylar fractures. Posterolateral type with brachialis muscle penetration and neurovascular injury. J Pediatr Orthop. 1999; 19:518.

15. Shim JS, Lee YS. Treatment of completely displaced supracondylar fracture of humerus in children by cross-fixation with three kirschner wires. J Pediatr Orthop. 2002;22:12-6.

16. Lee SS, Mahar AT, Miesen D, Newton PO. Displaced pediatric supracondylar humerus fractures: Biomechanical analysis of percutaneous pinning techniques. J Pediatr Orthop. 2002;22:440-3.

17. Flynn JC, Mattews JG, Beriot RL. BUCD pinning of displaced supracondylar fracture of humerus in children. J Bone Joint Surg. 1974;56-A:263-72.

18. Yadav UB, Singhal R, Tonk G, Aggarwal T, Verma AN. Crossed pin fixation in displaced supracondylar humerus fractures in children. Indian $\mathrm{J}$ Orthop. 2004;38:166-9.

19. Boparai R, Sharma R, Kapila R, Pandher DS, Diwan RP. Supracondylar fractures in children-closed reduction vs open reduction. Indian J Orthop. 2006;40:103-7.

20. Labelle H, Bunnell WP, Duhaine M, Poitras B. Cubitus varus defor mity following supracondylar fracture of the humerus in children. J PediatrOrthop. 1982;2:539-46.

21. Gordon JE, Patton CM, Luhmann SJ, Bassett GS, Schoenecker PL. Fracture stability after pinning of displaced supracondylar distal humerus fracture in children. J Pediatr Ortho. 2001;21:313-8.

22. Skaggs DL, Hale JM, Bassett J, Kaminsky C, Kay RM, Tolo VT. Operative treatment of supra condylar fractures of the humerus in children. the implications of pin placement. J Bone Joint Surg (Am). 2001;83:735-40.

23. Mostafavi HR, Spero C. Crossed pin fixation of displaced supracondy lar humerus fractures in children. Clin Ortho Relat Res. 2000;376:56-61.

24. Wilkins KE. Fractures and dislocations of the elbow region. In: Rockwood CA, Wilkins KE, King RE, eds. Fractures in Children. 3rd ed. New York:JB: Lippincott. 1991;509-28.

25. Kamath SU. Open reduction and internal fixation of severely displaced humeral supracondylar fractures in children. Indian J Orthop 2003;37:9.

26. Philip FC, William Mc, Mervyn L. An Analysis of open reduction of irreducible supracondylar fractures of the humerus in children.Canad J Surg. 1998;41:112-18.

27. Kumar R, Kiran EK, Malhotra R, Bhan S. Surgical management of the severely displaced supracondylar fractures of the humerus in children. Injury. 2002;33:517-22.

28. Ababneh M, Shannak A, Agabi S, Hadadi S. The treatment of displaced supracondylar fractures of the humerus in children. A comparison of three methods. Int Orthop. 1998;22:263-5.

29. Umar M, DSousa OP. Supracondylar fractures of humerus in children. An analysis of various treatment modalities at the Agha Khan University Hospital Karachi. Pakistan. Pak J Surg. 1991;7:16-22.

30. Diri B, Tomak Y, Karaismailoglu TN. The treatment of displaced fractures of the humerus in children (an evaluation of three different treatment methods). ULUS Trauma Der. 2003;9:62-9.

Cite this article as: Shobha HP, Vishwas K, Lingaraju K, Kumar G. Type-III supracondylar humerus fracture: functional outcome of open reduction and internal fixation after failed closed reduction. Int J Res Orthop 2021;7:62-5. 